\title{
Students' Epistemological Frames and Their Interpretation of Lectures in Advanced Mathematics
}

\author{
Victoria Krupnik \\ Rutgers University
}

\author{
Tim Fukawa-Connelly \\ Temple University
}

\author{
Keith Weber \\ Rutgers University
}

In this paper, we present a comparative case study of two students with different epistemological frames watching the same real analysis lectures. We show the general point that students with different epistemological frames can interpret the same lecture in radically different ways. We also identify epistemological frames that are useful or counterproductive for understanding a lecture on how the rational numbers are constructed from the integers. These results illustrate how different students interpretations of a lecture are not inherently tied to the lecture, but rather depend on the student and that student's perspective on mathematics. Thus, improving student learning may depend on more than improving the quality of the lectures, but also changing student's beliefs and orientations about mathematics and mathematics learning.

Key words: epistemic frames, student understanding of lecture, real analysis

In recent years, there has been a substantial increase in research into how proof-oriented university mathematics courses are traditionally taught. This research has led to important insights into what transpires in lectures in advanced mathematics (e.g., Fukawa- Connelly, 2012; Fukawa-Connelly \& Newton, 2014; Hemmi, 2010; Lew et al., 2016; Mills, 2014; Pinto, 2013; Weber, 2004; Weinberg et al., 2016) and mathematics professors' motivation for their pedagogical behavior (e.g., Alcock, 2010; Lew et al., 2016; Nardi, 2007; Weber, 2012).

While the nature of lecturing in advanced mathematics is now better understood, there has been comparatively little research into how tertiary students interpret the advanced mathematics lectures that they observe. The goal of the current paper is to address this gap. In particular, we aim to shed light on the issue: When professors provide lectures in advanced mathematics that are clear to other mathematicians, why are these lectures often confusing to the students who attend them? Why do some students learn from a lecture while other students find the same lecture less clear? What dispositions prepare students to learn from lectures in advanced mathematics?

To address these broad issues, we adapt the notion of epistemological frame. We elaborate on the nature of epistemological frames shortly, but an epistemological frame can be thought of as a person's tacit answer to the question, "what sort of activity is this?" (c.f., Goffman, 1997; Redish, 2004). In this paper, we present a comparative case study of two students with different epistemological frames watching the same real analysis lectures. The first goal of this paper is to illustrate the general point that students with different epistemological frames can interpret the same lecture in radically different ways. The second goal of this paper is to identify epistemological frames that are useful or counterproductive for understanding a lecture on how the rational numbers are constructed from the integers.

\section{Theoretical Perspective}

In this paper, we adapt the notion of epistemological frame, as it is used in the physics education literature (e.g., Redish, 2004). Goffman (1997) introduced the notion of frame to describe how individuals develop expectations to help them make sense of the complex social 
spaces that they inhabit. For instance, most adults in the Western world have a "restaurant frame" (Schank, 1990). When individuals enter a restaurant, they carry with them numerous assumptions: for instance, the individual will eat a meal, the staff at the restaurant will prepare the meal, the items listed on the menu list are what the individual may order, the prices next to the item denote how much the food will cost, the individual will be expected to pay for their meal using cash or a credit card, and so on. Such expectations are valuable in that they enable us to cope with the enormous complexity of most situations that we regularly encounter. However, occasionally our frames can be problematic in cases where they are inaccurate or when two different individuals frame the same situation in different ways. For instance, a visitor to the United States might not be aware of the expectation to leave a $20 \%$ tip on the bill, which could lead her to inadvertently insult the waiter by not leaving the presumed gratuity.

In an educational situation, we refer to an individual's epistemic frame as consisting of their epistemological expectations. These consist of an individual's responses to questions such as "what do I expect to learn?", "how do I build new knowledge?", and "what counts as knowledge or an intellectual contribution in this environment?" (cf., Redish, 2004). Physics educators have illustrated how when a teacher and her students approach an activity with different epistemological frames, the students may not reap the educational benefits that the teacher intended. For instance, Redish (2004) described one student in a physics tutorial who was given a prompt to make a qualitative prediction using her conceptual understanding of physical principles. However, this student viewed intellectual contributions in a physics classroom as consisting of deriving numerical answers from textbook formulas. As a result, she participated in the activity by engaging in computations, thereby avoiding the conceptual considerations the activity was designed to elicit. Hammer (1995) illustrated how epistemological frames can explain how some students successfully learn physics in a traditional classroom while other students do not.

In this paper, we use epistemic frames to account for two students' interpretations of a lecture in advanced mathematics. Although the phrase "epistemic frame" is not often used in mathematics education, mathematics educators have used similar constructs to highlight students' classroom participation and identify differences in how teachers and students sometimes frame mathematical activity. For instance, Thompson (2013) described a secondary algebra teacher, Sheila, whose discourse with students was saturated with references to the conceptual meaning of the operations that were being discussed and performed, and a student, Mindi, who struggled in Sheila's course. Through his interviews with Mindi, Thompson found that Mindi believed that doing algebra consisted of applying rules and learning algebra consisted of memorizing rules; Mindi saw little value to having a conceptual understanding of these rules. As a result, she ignored the frequent references to meaning in Sheila's discourse.

In advanced mathematics, Solomon (2006) and Alcock and Simpson $(2004,2005)$ have explored the relationship between students' epistemologies and their learning in advanced mathematics classrooms, with both emphasizing that students who believe mathematical knowledge comes from external sources have a difficult time in these environments. Similarly, many mathematics educators have documented how the types of arguments that students found convincing influenced their proof-related behavior (e.g., Harel \& Sowder, 2007; Stylianides, Stylianides, \& Weber, in press). In this paper, we consider a more fine-grained epistemological distinction than the ones discussed above. The two students that we considered both showed evidence of having a desire to understand the material that they were learning, an internal loci of control and deductive proof schemes. Nonetheless, their different epistemological frames led 
them to interpret the same real analysis lecture in very different ways.

\section{Methods}

\section{Rationale}

The goal of this study was to understand individual student's interpretations of a real analysis lecture at a fine-grained level. Doing this in an authentic manner posed significant methodological difficulties. If we observed students in an actual real analysis lecture, it would be infeasible for us to know how a student was interpreting a professor's comments in the moment since we would be unable to interrupt the lecture to probe the student's thinking. We could follow Lew and colleagues (2016) in using cued recall by interviewing a student about a lecture they attended shortly after the lecture had occurred. However, by that time, much of the student's initial impressions would be forgotten. To manage this difficulty, we interviewed two students as they watched real analysis lectures that had previously been posted on YouTube. Here, the students can act as if they were attending an actual lecture yet the interviewer or student could pause the video to discuss their in-the-moment impressions of what was being discussed.

In this paper, we report a comparative case study (Yin, 2013) in which we attempt to illustrate how a particular phenomenon unfolds within a given context. There are some particular nuances of the study, such as the individual students' backgrounds or the content of the lecture, that may not generalize to other situations. What we contend is representative is the phenomenon of how an individual student's epistemological frame can influence his or her understanding of a mathematics lecture.

\section{Participants}

Two participants, Alan and Brittany (pseudonyms), agreed to participate in this study. Both participants were mathematics majors at a large state university in the northeast United States. Both students had completed a transition-to-proof course in the previous semester. At the university in which this study occurred, mathematics majors were required to complete a course in real analysis, for which the transition-to-proof course was a prerequisite. Some mathematics majors enrolled in real analysis in the semester after completing their transition-to-proof course while others, like Alan and Brittany, did not. Like many mathematics majors, Alan and Brittany elected to take an abstract algebra course immediately after their transition-to-proof course, choosing to postpone their real analysis requirement to a subsequent semester. Hence, while neither had, both participants could have taken a real analysis course in the semester of this study.

\section{Procedure}

The materials consisted of the first two 60 minute class meetings from a real analysis course taught by the president of the Mathematics Association of America and award winning professor Francis Su at Harvey Mudd University ${ }^{1}$. The lectures consisted of Professor Su beginning the real analysis course by first constructing the rational numbers and then the real numbers from the integers. Prior to conducting the study, the research team studied the lecture and parsed the lecture into five to ten minute segments in which coherent mathematical content was being

1 Videos can be found at: http://analysisyawp.blogspot.com 
presented. The research team also identified points in the lecture where important content was being conveyed.

Each participant met weekly with the first author for four weeks. Each of the four interviews was audio-recorded. The first interview was a one-hour interview in which the participant discussed the content from the transition-to-proof course to get a sense of their understanding of the relevant content (particularly with number theory, functions, and proof) as well as their learning strategies and dispositions. The next three interviews were two-hour interviews conducted in the style of a constructivist teaching experiment (Steffe \& Thompson, 2000) in which the research team attempted to build and refine the mental schemes, which we termed epistemological frames, that each participant was using to interpret the real analysis lectures. During each interview, the participant watched the lecture and was instructed to stop the tape to discuss anything that they observed to be important, interesting, confusing, or otherwise noteworthy. The interviewer would also stop the tape to probe the participant's thinking when the professor had stated something that the research team had identified as important or at the end of a segment. The interviewer would then ask the participant to describe their impressions at that point.

After each interview, the members of the research team would engage in concurrent analysis by listening to the recordings of the interview and forming initial hypotheses about the schemes that the participants were using to interpret the lectures. They would then meet to synthesize these hypotheses and develop prompts to assess the viability of their hypotheses. These prompts were designed such that if a participant held a particular epistemological frame, we could expect them to respond in a particular way. We began the next interview segment by providing participants with these prompts, which was then followed by them resuming watching the lecture videos.

After all four interviewers were conducted, we transcribed all four interviews and clarified our initial hypotheses of participants' epistemological frames from the prior concurrent analysis. We then engaged in the following cyclic retrospective analysis: For each aspect of a participant's hypothesized epistemological frame, each member of the research team individually read the transcripts, identifying all instances that either supported or disconfirmed that the participant held this frame. The research team then met to determine how well the proposed epistemological frame was supported by the data. When there were aspects of the hypothesized frames that were not supported by the data (i.e., there were few confirming instances or significant disconfirming instances), we either removed this aspect from the epistemological frames that we attributed to the students or we revised the epistemological frame and repeated our analysis. The result of this retrospective analysis were epistemological frames for Alan and Brittany that were grounded in our data.

\section{Results}

\section{Epistemological Frames}

For the sake of brevity, we briefly discuss four aspects of Alan and Brittany's epistemological frames. In our presentation, we will elaborate on these and provide supporting evidence. We first note two aspects that Alan and Brittany had in common: (i) Both participants appreciated, understood, and enjoyed mathematical proof and (ii) both exhibited an internal locus of control. We also note two areas in which they differed: (iii) Alan valued definitions of terms that were unambiguous while Brittany preferred definitions that were comprehensible and relatable to her prior ways of knowing, and (iv) Alan viewed the purpose of these lectures as 
making his understanding of the rational numbers more reliable by basing it on a more secure footing (the reliability of the integers) while Brittany viewed the purpose of the lectures as providing a common base of knowledge shared by all students in the class from which real analysis can be built.

Differing interpretations of the lecture. We note that Brittany's epistemological frames, while sensible and productive in some situations, led her to interpret some aspects of the lecture in unproductive ways. For instance, when Professor Su deduced common properties of the real numbers (e.g., the integers were contained in the rationals), Brittany became frustrated because this was obvious and "everyone already knew this". By contrast, Alan claimed that the point of the lecture was to illustrate how Professor Su's construction of the rational numbers was sufficient to prove these important properties (cf., Weber, 2002). Brittany found many of Dr. Su's proofs of common facts about the rational numbers to be unnecessarily complicated, since she was aware of simpler proofs of these statements that were appropriate for middle school students. For instance, Professor Su defined rational numbers as equivalence classes of ordered pairs and defined addition as $(a, b)+(c, d)=(a d+b c, b d)$. Professor Su then proved this operation was well-defined. Brittany thought that the simple proof that $a / b+c / d=a d / b d+b c / b d$ $=(\mathrm{ad}+\mathrm{bc}) / \mathrm{bd}$ was superior to Professor Su's formal demonstration. In contrast, Alan abhorred the suggestion of using such a proof, since we had no right at this stage to say $a / b=a d / b d$. To Alan, the point of this exercise was to ignore everything we knew about the rational numbers. In general, Brittany wanted to apply her robust understanding of the rational numbers to the content that Professor Su was discussing and was annoyed that Professor Su did not do so. Alan continually reminded himself that he was only allowed to consider what he knew about the integers, the definitions Professor Su had provided, and the deductions made from them.

\section{Discussion and significance}

We use the general finding that students' epistemological frames can enable or prevent students from interpreting mathematical lectures in a productive manner to make two points. First, previous research on lectures in advanced mathematics has generally focused on what the professor says but did not consider student's interpretation of what was said. Our results illustrate how students' interpretations of a lecture are not inherent in the lecture itself but also depend on the student doing the interpreting. Consequently, we argue that ignoring students' interpretations of lectures is a significant shortcoming of most studies on lectures in advanced mathematics. Second, our results suggest that the key to improving students' learning from lectures does not consist only of improving the quality of the lectures. Rather, it is important to attend to their epistemological frames as well, a point that Solomon (2006) and Dawkins and Weber (in press) argue has received limited attention in the mathematics education literature. 


\section{References}

Alcock, L. (2010). Mathematicians' perspectives on the teaching and learning of proof. Research in collegiate mathematics education VII, 63-91.

Alcock, L., \& Simpson, A. (2004). Convergence of sequences and series: Interactions between visual reasoning and the learner's beliefs about their own role. Educational Studies in Mathematics, 57(1), 1-32.

Alcock, L., \& Simpson, A. (2005). Convergence of sequences and series 2: Interactions between nonvisual reasoning and the learner's beliefs about their own role. Educational Studies in Mathematics, 58(1), 77-100.

Dawkins, P. \& Weber, K. (in press). Values and norms of proof for mathematicians and students. To appear in Educational Studies in Mathematics.

Fukawa-Connelly, T. P. (2012). A case study of one instructor's lecture-based teaching of proof in abstract algebra: making sense of her pedagogical moves. Educational Studies in Mathematics, 81(3), 325-345.

Fukawa-Connelly, T. P., \& Newton, C. (2014). Analyzing the teaching of advanced mathematics courses via the enacted example space. Educational Studies in Mathematics, 87(3), 323- 349.

Goffman, E. (1997). The Goffman reader. New York: Wiley-Blackwell. Hammer, D. (1995). Epistemological considerations in teaching introductory physics. Science

Education, 79(4), 393-413. Harel, G., \& Sowder, L. (2007). Toward comprehensive perspectives on the learning and teaching of proof. Second handbook of research on mathematics teaching and learning, 2, 805-842.

Hemmi, K. (2010). Three styles characterising mathematicians' pedagogical perspectives on proof. Educational studies in mathematics, 75(3), 271-291.

Lew, K., Fukawa-Connelly, T. P., Mejía-Ramos, J. P., \& Weber, K. (2016). Lectures in advanced mathematics: Why students might not understand what the mathematics professor is trying to convey. Journal for Research in Mathematics Education, 47(2), 162-198.

Mills, M. (2014). A framework for example usage in proof presentations. The Journal of Mathematical Behavior, 33, 106-118.

Nardi, E. (2007). Amongst mathematicians: Teaching and learning mathematics at university level (Vol. 3). Springer Science \& Business Media.

Pinto, A. (2013). Revisiting university mathematics teaching: A tale of two instructors. In Eighth Congress of European Research in Mathematics Education (CERME 8), Antalya, Turkey.

Redish, E. F. (2004). A theoretical framework for physics education research: Modeling student thinking. arXiv preprint physics $/ 0411149$. 
Schank, R. C. (1990). Tell me a story: A new look at real and artificial memory. Charles Scribner's Sons.

Solomon, Y. (2006). Deficit or difference? The role of students' epistemologies of mathematics in their interactions with proof. Educational Studies in Mathematics, 61(3), 373-393.

Steffe, L. P., \& Thompson, P. W. (2000). Teaching experiment methodology: Underlying principles and essential elements. Handbook of research design in mathematics and science education, 267-306.

Stylianides, G., Stylianides, A., \& Weber, K. (in press) Research on the teaching and learning of proof: Taking stock and moving forward. In J. Cai (Ed). The compendium for research in mathematics education. NCTM: Washingston, DC.

Thompson, P. W. (2013). In the absence of meaning.... In Vital directions for mathematics education research (pp. 57-93). Springer New York.

Weber, K. (2002). Beyond proving and explaining: Proofs that justify the use of definitions and axiomatic structures and proofs that illustrate technique. For the Learning of Mathematics, 22(3), 14-17.

Weber, K. (2004). Traditional instruction in advanced mathematics courses: A case study of one professor's lectures and proofs in an introductory real analysis course. The Journal of Mathematical Behavior, 23(2), 115-133.

Weber, K. (2012). Mathematicians' perspectives on their pedagogical practice with respect to proof. International Journal of Mathematical Education in Science and Technology, 43(4), 463482.

Weinberg, A., Fukawa-Connelly, T., \& Wiesner, E. (2015). Characterizing instructor gestures in a lecture in a proof-based mathematics class. Educational Studies in Mathematics, 90(3), 233258.

Yin, R. K. (2013). Case study research: Design and methods. Sage publications. 